$$
\text { 会i- }
$$

\title{
La reflexividad de la investigación social y anamnesis.
}

\author{
J. Angel Bergua \\ DEPARTAMENTO DE PSICOLOGÍA Y SOCIOLOGÍA \\ UNIVERSIDAD DE ZARAGOZA
}

En la modernidad lo social se hace y se piensa en términos endógenos, no desde instancias exteriores, como sucedió en la premodernidad. La sociología y la política son modos relacionados entre sí de hacer y saber sobre lo social ensayados por las elites y que se deben a lo instituido. Sin embargo, la modernidad se caracteriza también por el hecho de que la sociedad saca fuerza de la continua desintegración de la sociedad instituida. Esa desintegración permite liberar lo instituyente. A esta liberación podemos denominarla anamnesis. Hay varias clases de anamnesis si distinguimos su carácter provocado/espontáneo 0 local/global. Las técnicas de investigación social encuadradas en la perspectiva dialéctica (como el Análisis Institucional y la Investigación-AcciónParticipativa) provocan anamnesis locales. La pregunta que cabe hacerse es si es posible provocar anamnesis globales.

Palabras clave: técnicas de investigación, instituido/instituyente, autoorganización, complejidad 


\section{La reflexividad de la investigación social y anamnesis}

J. Angel Bergua

\section{Introducción.}

Cierta sociología francesa ha utilizado el par de conceptos "instituyente" e "instituido para comprender lo social no como ha sugerido gran parte de la sociología desde Comte, como un sistema en equilibrio o cercano a él, sino como tienden a describir la realidad las ciencias duras, en términos metaestables o alejados del equilibrio. Así, por ejemplo, Maffesoli (1992: 87) dice que la única ley irrefutable de la vida social es la del "va y viene" continuo e incesante que se establece entre lo instituyente, "fuerza siempre renovada del estar juntos", y lo instituido, forma de sociabilidad fijada y codificada institucionalmente. Aunque habitualmente parece que lo social se resume perfectamente en la institución, cualquiera que ésta sea, hay momentos en que lo social instituyente irrumpe y emprende su tarea sin mediación ninguna, son los momentos de revolución. Con este esfuerzo encargado a lo instituyente lo social busca proporcionarse de nuevo una institución para existir en ella. Sin embargo, cuando esta institución queda planteada lo social instituyente se aparta, toma distancia, se encuentra, otra vez, en otro lado (Lourau, 1988: 90).

Esta tensión entre lo instituyente y lo instituido que se vuelve patente en situaciones tan inestables como el pánico o las revoluciones, también se da en situaciones aparentemente estables. Lo que ocurre es que tal tensión es en gran medida 
latente y, por lo tanto, no directa o inmediatamente observable. Sin embargo, si que pueden resultar patentes ciertos indicios de esa tensión. En ese caso el analista deberá sospechar de lo instituido y alcanzar lo instituyente que tiene que ver con tales indicios.

Si enfatizáramos la mayor relevancia de lo instituido lo instituyente aparecería como el ruido o el desorden que impiden la realización del orden "natural" de la sociedad. Ahora bien, si cambiamos el punto de observación y enfocamos el fenómeno no desde una región privilegiada de lo social sino atendiendo a su totalidad, el ruido y el desorden aparecen como manifestaciones de un orden interno que contrapesa la fuerza con la que lo instituido intenta absorber lo instituyente.

En la actual crisis de la Modernidad, caracterizada por el derrumbe de los grandes metarrelatos ideológicos, la presencia de anamnesis ha sido constatada por bastantes analistas. Para Guattari (1990: 69-72) el retorno de lo antiguo está en la base de la contemporánea explosión de ciertos "neoarcaísmos sociales" que, en su opinión, generan nuevos modos de valoración que espontáneamente se oponen al capital como equivalente general. Lipovetsky (1987: 205) parece aludir a algo parecido cuando, al referirse a la postmodernidad, habla de un proceso cool de desgaste de las representaciones modernas al que acompaña un proceso hard de liberación de actividad afectual libre. Por su parte, Duvignaud (1990: 191-92, 103) se ha fijado en esas "brechas" de la conciencia colectiva por las que emergen "líbidos" que "no encuentran ningún objeto que las satisfaga" y "subtextos" que revelan al "proceso conceptual tranquilizador" la existencia de un "abismo infranqueable". Finalmente, para Maffesoli (1992: 157; 1982: 201; 1993b: 18), el "retorno de lo inhibido" permite la "anamnesis" del estar juntos, la sociabilidad más elemental de lo social. Como se aprecia, distintas pero convergentes evaluaciones acerca de un mismo fenómeno del que genéricamente podemos decir que, en un mismo movimiento, por un lado rompe la continuidad del orden valorativo o representativo de la sociedad, y por otro permite asomar afectos y sociabilidades primarias ${ }^{1}$. 
Las observaciones anteriores muestran una importante analogía entre las anamnesis sociales y las psíquicas a las que el psicoanálisis se enfrenta a través de síntomas, sueños, lapsus, etc. Por lo tanto, es conveniente tomar nota de lo que el psicoanálisis ha dicho sobre las anamnesis psíquicas para inspirar el análisis de las anamnesis sociales. De los distintos modelos que proporcionara el psicoanálisis freudiano para comprender la complejidad de las subjetividades una vez constatada la importancia del inconsciente, para nuestro propósito resulta útil la economía de su primera tópica (Freud, 1982) pues con ella se describe una interacción entre los subsistemas consciente e inconsciente muy parecida a la que observamos en lo social entre lo instituido y lo instituyente. El modelo freudiano puede ser resumido en los siguientes puntos:

a) Se distinguen los "procesos psíquicos primarios" del inconsciente, que atienden a una realidad intrapsíquica y que se organizan en torno a la condensación y el desplazamiento (metáfora y metonimia, respectivamente, según la interpretación lacaniana), de los "procesos psíquicos secundarios" del preconsciente y la conciencia, gobernados lógicamente por los principios de identidad, no contradicción y tercero excluso, y afines semánticamente al principio de realidad impuesto por la sociedad instituida.

b) Aunque los instintos tienden a un fin, el de lograr una satisfacción orgánica ligándose a un objeto, a causa de una represión primitiva son fijados a representaciones inconscientes. A esta represión primera se suman otras posteriores que recaen sobre las ramificaciones psíquicas de la representación reprimida o sobre aquella serie de ideas procedentes de fuentes distintas que han entrado en conexión asociativa con dicha

1 Estos retornos de lo reprimido no son sólo objeto de atención para los científicos sociales. Prigogine y Stengers (1990: 43) han señalado también en relación a las ciencias duras que "las cuestiones negadas no desaparecen después de haber sido declaradas ilegítimas, sino que su insistencia ha provocado la inestabilidad del desarrollo científico y lo ha hecho vulnerable a problemas menores a primera vista". Y es que a pesar del logocentrismo, la praxis nunca muere porque lo real no puede ser absolutamente representado ni suplantado. 
representación. Sólo cuando las ramificaciones se han distanciado suficientemente de la representación reprimida pueden encontrar libre su acceso a la conciencia.

c) Las represiones del preconsciente no se efectúan sobre la idea o representación directa de la cosa en cuestión, que permanece inaccesible en el inconsciente, sino sobre su carga afectual o sentimental, pues es a ella a la que se adjudican representaciones sustitutivas en cada ocasión que intenta manifestarse. Al mismo tiempo que contienen la carga, para acabar de proteger el sistema, efectúan una contracarga con el mismo montante de afecto.

d) Cuando el trabajo de la represión es perfecto, el preconsciente no permite el paso de ninguna idea inconsciente y desde la exterioridad de la conciencia es imposible dar cuenta de lo que ha sucedido. En cambio cuando la represión ha resultado parcial o totalmente fallida es cuando el retorno de lo reprimido, la movilización de representaciones lingüísticas y la estratificación de la subjetividad se tornan transparentes.

e) No obstante, la represión del inconsciente no sólo la efectúa el yo del individuo. La terapia psicoanalítica da la impresión de ser un esfuerzo suplementario ejercido por el principio de realidad, en alianza con la sociedad, para reprimir esos impulsos incompatibles con lo instituido y volver a hacer funcionar la censura preconsciente. Más aún, si este esfuerzo represivo suplementario de aspecto amable resulta también fallido, la sociedad activará otros mecanismos explícitamente represivos y encerrará a los sujetos².

2 Varela y Alvarez Uría (1986: 74) han señalado, en relación a la psicología, que si "ha tenido cabida al lado de la medicina, la psiquiatría y la policía, se debe a que aportaba soluciones específicas de control: por un lado, ocupaba el campo de la mente dejando para los médicos el cuidado del cuerpo; por otro, se centraba en el espacio extramanicomial para resolver conflictos que no implicabn una ruptura de la identidad personal (neurosis, en general); finalmente, se mantenía en un espacio aséptico y científico dejando para la polcía los trabajos más rudos e impopulares. J ustificaba, a su vez, el ámbito de la vigilancia dulce, ya que para la psicología todos los ciudadanos son peligosos en potencia, susceptibles de ser tratados y adaptados" 
Según lo anterior se deduce que hay distintas clases de anamnesis psíquicas. En primer lugar, hay anamnesis locales tuteladas por el psicoanálisis, como sucede con la "asociación libre", esa técnica que busca afianzar la estabilidad anímica del individuo recuperando con la palabra lo reprimido que le hace sufrir para restablecer el dominio del yo (así como de la sociedad, que actúa como su principio de realidad) y volver a someter los impulsos inconscientes. En segundo lugar, hay anamnesis locales espontáneas, como las que tienen lugar en sueños, lapsus y síntomas, en las que lo inconsciente brota sin ayuda de ningún dispositivo. El yo experimentará esas afirmaciones de lo inconsciente en términos de angustia. En tercer lugar, hay anamnesis globales espontáneas, caso de los delirios y de las psicosis en general, en las que irrumpe un gran montante de impulsos inconscientes debido a que la estructura consciente está muy debilitada. En estos casos, como la conciencia es incapaz de hacer compatible tales impulsos con el principio de realidad proveniente de la sociedad, ésta encerrará a los sujetos. Lo que dejan claro estas actuaciones coercitivas es la imposibilidad de acuerdo entre el principio de placer y el de realidad y que se apuesta decididamente por la realidad instituida. No obstante, ha habido bastantes autores que han entendido estas patologías no como un problema del individuo sino de la sociedad, que no sabe acoger esos nuevos impulsos que trae consigo el sujeto. $Y$ como han entendido que estos nuevos impulsos podrían regenerar una sociedad desequilibrada y enferma han apostado por ellos. De ahí la necesidad de esa cuarta clase de retorno de lo reprimido, la anamnesis tutelada global, con la que se intentaría refundar lo social a partir de los impulsos inconscientes. Uno de los modos como se ha sugerido provocar anamnesis globales es el uso del esquizoanálisis (Deleuze y Guattari, 1985), que no se inspira en las estructutras yoicas derivadas del complejo de Edipo sino en el mundo que trae consigo pero no puede terminar de realizar el esquizofrénico.

La pérdida de validez del principio de realidad que las anamnesis traen consigo no sólo debilita al yo y a la sociedad. 
También esa palabra, el logos, en el que tanto confiara Freud, se ve desbordada por la acción. Es por eso que si se toma realmente en serio el asunto de las anamnesis resulta más útil Reich que Freud (Lapassade, 1996: 35-37 y 57). En efecto, éste considera que la represión tiene lugar sobre un recuerdo y que de esa represión derivará un fantasma luego expresado a través de un síntoma somático. En cambio Reich considera que la represión se efectúa sobre un deseo bio-psicológico del que derivarán ciertos síntomas que posteriormente darán lugar a fantasmas. En un caso prima el orden de la palabra y de la representación mientras que en el otro lo importante es el cuerpo y el acto. Como sentencia Lapassade, el psicoanálisis de Freud es sólo una logoterapia: "siempre se trata de hablar y sólo de eso". En cambio, en la vegetoterapia de Reich "hablar es una resistencia": es uno de los medios utilizados para suprimir (re-presentando) la actividad corporal o excitación vegetativa.

En el campo social esto implica que la logoterapia practicada con las técnicas de investigación clásicas (no sólo las cuantitativas sino las cualitativas principalmente, pues son éstas las que más se entretienen con la palabra) y la discusión política que impulsa nuestra democracia no son suficientes. Quizás la democracia y la investigación social sean, como el psicoanálisis en opinión de Reich, simplemente una resistencia. Una resistencia a lo instituyente.

\section{La Investigación social}

Para Ibáñez (1985a: 14) la anamnesis ("desligar lo que está ligado por represión, liberar las posibilidades de funcionamiento reprimidas por la memoria, transformar la memoria en conciencia"), es la operación fundamental de cualquier ciencia en relación a un inconsciente biográfico, en las psicologías y a un inconsciente histórico, en las sociologías. Por su parte Martín Santos (1988: 221) ha propuesto el término más amplio de "anagnórisis" para indicar los momentos en que el poder, más allá de legitimaciones, revela su verdadero carácter. Ibáñez y 
Martín Santos no están hablando de las ciencias en términos de control social sino de liberación. Están haciendo, por lo tanto, un uso crítico de la ciencia social, en concreto de la sociología. Sin embargo, el saber científico ya hemos visto que se debe a lo instituido. ¿Por qué entonces lo instituido reclama la presencia de lo instituyente provocando anamnesis?. Pues porque lo instituido necesita de lo instituyente y la sociología es un instrumento que satisface esa necesidad. Lo hace tanto con las teorías (que interpretan la información) como con las técnicas de investigación (que producen dicha información). Ambos momentos no son independientes. Se reúnen en la producción de conocimiento científico. Sin embargo, pueden ser tratados por separado. Por razones de espacio dejaremos de lado las teorías y veremos qué tienen que ver las técnicas de investigación social con las anamnesis. Para ello seguiremos a Ibáñez (1985)

A la hora de tratar de las técnicas de investigación social se puede hacer desde distintos puntos de vista. En primer lugar, podemos prestar atención a CÓMO deben utilizarse, aspecto éste que tiene que ver con el nivel tecnológico de la investigación y sobre el que se preocupan sobre todo los investigadores que trabajas con técnicas cuantitativas (que luego denominaremos "distributivas"). En segundo lugar, se puede prestar atención al nivel metodológico, que presta atención a POR QUÉ se deben usar las técnicas de tal modo y no de otro. Es éste un nivel superior al tecnológico pues explica las condiciones del cómo de la investigación social, la razón de los pasos que se deben dar y la lógica que inspira el proceso de investigación desde el comienzo hasta al final. Es cierto que el término método hace referencia también al tratamiento que se da a la información una vez que es obtenido con las técnicas para darle cierto sentido y permitir ya su relación con las teorías. Sin embargo, entre la ciencia clásica y la misma filosofía de la ciencia contemporánea cuando se habla de método es para referirse a la lógica de la investigación. Este nivel ha interesado especialmente a las técnicas cualitativas (que luego dividiremos en "estructurales y "contextuales"). 
Cuadro 1. Niveles de reflexión sobre las técnicas de investigación social.

DISTRIBUTIYA ESTRUCTURAL CONTEXTUAL DIALECTICA

\section{NIYEL EPISTEMOLOGICO (PARA OUE)}

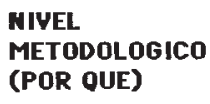

NIVEL. METODOLOGICO (POR QUE)

NIYEL. TECNOLOGICO ¿COMO?
No interesa

(adaptación a la demanda)

No interesa (adaptación a la estadistica)

Si interesa (invención de técnicas)

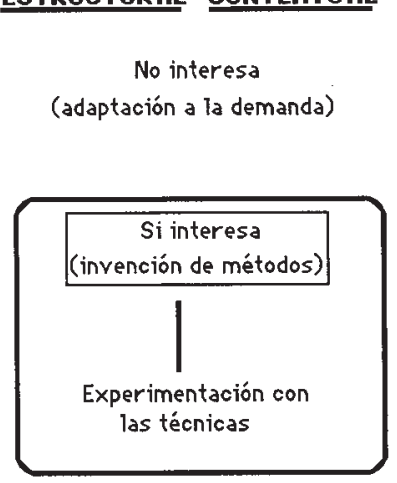

Si interes (invención de necesidades)

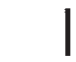

Experimentación con los métodos

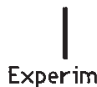
Experimentación con las técnicas

Por último, un tercer modo de tratar el asunto de la investigación es observándola desde un nivel superior al metodológico, el que se preocupa por el PARA QUÉ de la investigación y que se puede denominar epistemológico. En realidad el término epistemología hace referencia al conocimiento del conocimiento. Sin embargo, en las últimas décadas ha sido utilizado con sentidos bien diferentes. El sentido que aquí se le adjudica deriva de la cibernética de segundo orden. Maturana y Varela (1990: 21) han inferido de sus investigaciones acerca de la biología del conocimiento y del reconocimiento de que no reflejamos el mundo sino que lo inventamos una importante conclusión epistemológica: "todo lo dicho es dicho por un observador". Pues bien, en términos sociológicos, si observamos al observador que investiga está claro que debe interesar la función que cumple lo que dice o investiga en el entorno social en el que se desenvuelve. Esto es precisamente lo que lleva a preguntar por el PARA QUÉ de la investigación. Esta pregunta es ineludible cuando se usan las técnicas de investigación-acción (que luego denominaremos "dialécticas")

Aunque a menudo se ha esgrimido la distinción cuantitativo/cualitativo para clasificar técnicas y métodos diferentes hay bastantes autores, como lbáñez, que consideran inadecuada 
tan simple separación pues, en realidad, desde un punto de vista epistemológico, las técnicas cualitativas y las cualitativas no son muy diferentes. En efecto, si prestamos atención al contexto social en el que se inscribe no sólo la investigación sino la demanda de la misma y lo que se va a hacer con la información obtenida, para él estaba claro que con las encuestas, grupos de discusión, entrevistas, observaciones, etc. siempre sucede que el Estado y el Capital o sus representantes encargan investigaciones a los sociólogos para poder ser más efectivos a la hora de planificar políticas públicas, estrategias de marketing, etc. De modo que la investigación social formaría parte de un dispositivo de control o de un modo de organización heterónomo de lo social por el que las élites obtendrían información de lo instituyente y le inyectarían algo de orden (neguentropía, entropía negativa). Dicho de otro modo, de lo que se trata es de institucionalizar lo instituyente sometiéndolo a la lógica de lo instituido. Pues bien, frente a esta práctica investigadora que apuesta por el dominio de lo instituido, Ibáñez sugirió tener en cuenta otra concepción de lo social en la que lo instituyente se liberaría de lo instituido. En esta otra manera de entender lo social se inscribirían técnicas como el Análisis Institucional, desarrollado en Francia en la última mitad del siglo XX, la Investigación-Acción-Participativa, exportada desde Latinoamérica, y las distintas clases de intervenciones sistémicas que ha inspirado la Escuela de Palo Alto. Sin embargo, antes de ver las posibilidades que abren estas técnicas para la liberación de lo instituyente conviene ver más características del conjunto de ellas para tomar conciencia de las limitaciones que, en general, plantean para la liberación de lo instituyente.

El paradigma complejo propuesto por lbáñez distingue los niveles teconológico, metodológico y epistemológico mencionados pero los combina con la distinción de tres perspectivas o clases de técnicas diferentes: la distributiva, la estructural y la dialéctica o sistémica. Pero quizás sea necesario incluir una perspectiva más, la contextual, que se ubicaría entre la estructural y la dialéctica. Las diferencias entre las cuatro perspectivas pueden observarse tanto en términos metodológicos como epistemológicos. 


\subsection{Nivel metodologíco: ¿Por qué?}

Desde un punto de vista metodológico las cuatro perspectivas se diferencian en las respuestas que dan a una serie de cuestiones. La primera es el tipo de "juego de lenguaje" que utilizan. La razón por la que Ibáñez habla de juego de lenguaje es doble. Por un lado, está influido por las reflexiones del segundo Wittgenstein y la pragmática acerca de que el lenguaje, más que para significar, está para ser usado. En este sentido, la investigación social consiste en la utilización de ciertos usos o juegos del lenguaje que se dan en la vida cotidiana.

En efecto, la encuesta estadística, técnica emblemática de la perspectiva distributiva, utiliza el juego de lenguaje "pregunta/respuesta" pues los investigadores se enfrentan a las unidades de la muestra con un cuestionario previamente elaborado y les obligan a responder eligiendo uno de los ítems propuestos. En cambio las técnicas encuadradas en la perspectiva estructural, como el grupo de discusión o la entrevista en profundidad, utilizan juegos de lenguaje tipo "conversación" que también funcionan de un modo espontáneo en la vida cotidiana. Por su parte, las técnicas de la perspectiva contextual, como las historias de vida o la observación, activan un juego de lenguaje participativo que copia de la realidad el contexto (pasado en las historias de vida y presente en la observación) y la praxis. Finalmente, las técnicas encuadradas en la perspectiva dialéctica o sistémica utilizan un juego de lenguaje tipo "asamblea" que, como las asambleas reales, sirven para discutir y tomar decisiones que alterarán o intentarán alterar la realidad.

La clasificación de las técnicas de investigación social según el juego de lenguaje que utilizan permite enunciar una muy importante regla acerca de qué técnica a utilizar para investigar un fenómeno dado. La regla postula una relación de isomorfismo entre el juego de lenguaje o situación generada experimentalmente con cada técnica y el juego de lenguaje 0 situación social real en que se inscribe el fenómeno que vamos a investigar. Así, puesto que la encuesta estadística utiliza el juego de lenguaje pregunta/respuesta según ha sido definido 
antes, podrá servir para investigar fenómenos inscritos en juegos de lenguaje o situaciones similares. Es el caso, por ejemplo, de los estudios sobre intención de voto o de compra pues en ambos casos hay una lista de partidos o de productos entre los que el individuo ha de elegir. Con un cuestionario podemos reproducir una situación social similar: preguntamos "¿a quién va a votar en las próximas elecciones?", "¿qué clase de detergente suele comprar?", etc. y ofrecemos una lista de los partidos o de productos existentes para que elija.

En el caso del grupo de discusión, técnica emblemática de la perspectica estructural, el juego de lenguaje tipo "conversación" permite investigar fenómenos inscritos en situaciones o juegos de lenguaje similares. Tales fenómenos son principalmente los de opinión publica pues desde Tarde sabemos que se crean a través de las redes informales de conversaciones que tejen nuestra vida cotidiana y en las que, incluso, quedan absorbidas las informaciones distribuidas por los medios de comunicación de masas. De modo que con el grupo de discusión reproducimos experimentalmente el contexto social, la conversación, en el que se produce opinión.

En el caso de la observación participante, la técnica que mejor representa a la perspectiva contextual, la utilización de la participación permite obtener información, a través de la experiencia subjetiva, del sentido depositado en el contexto y que comparten los actores. Es por eso que con esta técnica se pueden investigar las culturas implícitas y no siempre del todo conscientes que anónimamente producen y reproducen las gentes en su vida cotidiana.

Por último, en el caso de la perspectiva dialéctica, en la que se incluyen técnicas como el Análisis Institucional (o el sociopsicoanális), la Investigación Acción Participativa y las terapias sistémicas, el juego de lenguaje tipo "asamblea" permite analizar fenómenos como los de cambio o conflicto social pues también en ellos, aunque de un modo espontáneo, tienden a generarse asambleas en las que se discute acerca de cómo es la realidad y se decide emprender tal o cual acción. 
Cuadro 2. Técnicas de investigación de las perspectivas distributiva, estructural, contextual y dialéctica.

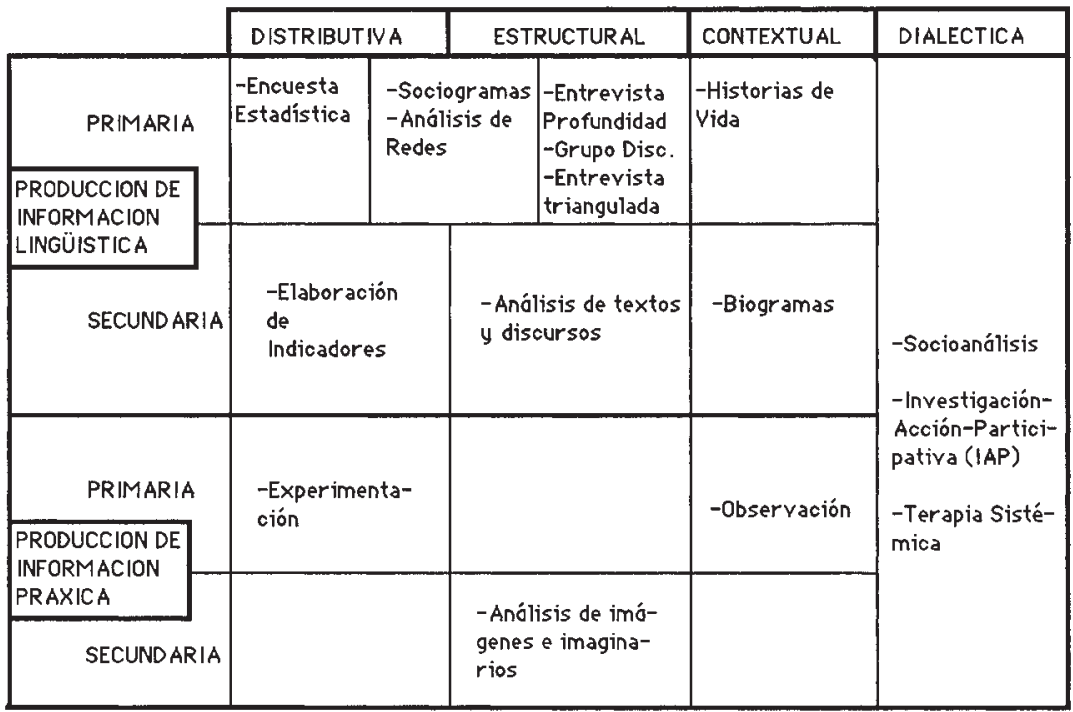

El hecho de que Ibáñez preste atención solamente al juego de lenguaje le impide dar cabida en su clasificación a aquéllas técnicas en las que no se obtiene información acerca de lo que se dice sino acerca de lo que se hace. En el caso de la perspectiva distributiva nos encontraríamos con un juego de interacción tipo "estímulo/respuesta" que es precisamente el que utiliza la experimentación. En el caso de la perspectiva estructural aunque no hay ninguna praxis análoga al juego de lenguaje tipo conversación puede incluirse el análisis de imágenes (video, fotografías, etc.) y de imaginarios colectivos a partir de información previa. En la perspectiva contextual el juego de lenguaje participativo incluiría la producción de información lingüística y estaría plenamente desarrollado en la observación participante ya que con las historias de vida la única praxis que se tiene en cuenta es la vivida. Del mismo modo, en la perspectiva dialéctica, el Análisis Institucional, la Investigación Acción Participativa o las intervenciones sistémicas, el juego de lenguaje tipo asamblea sería, a la vez, una praxis pues en ella no sólo se dice pues también se hace. Sin 
embargo, este hacer de la perspectiva dialéctica no reproduce lo instituido, como sucede en la perspectiva contextual, sino que libera lo instituyente y promueve cambios.

Pero para acabar de clasificar las distintas técnicas de investigación en las perspectivas mencionadas es necesario tener en cuenta que hay técnicas que permiten producir información primaria y que existen otras técnicas encargadas de producir información secundaria a partir de información ya disponible. En este sentido, si en la perspectiva distributiva la encuesta estadística permite producir información primaria, la elaboración de indicadores produce información secundaria. Y lo mismo sucedería en el resto de perspectivas. El cuadro 2 clasifica, teniendo en cuenta este último criterio y los mencionados más arriba, gran parte de las técnicas de investigación.

Además del juego de lenguaje o el tipo de praxis utilizado para producir información una segunda cuestión que debe tenerse en cuenta para singularizar las cuatro perspectivas mencionadas es cuál es el componente de la lengua o de la acción al que se presta atención. En el caso de la distributiva, si observamos la encuesta estadística, es el componente referencial, pues lo que interesa es el referente, lo denotado. En cambio en la perspectiva estructural lo que interesa es la dimensión estructural del componente simbólico: no lo que lo dicho o hecho pueda denotar sino lo que connote. Si en el caso anterior se hacía referencia a la capacidad de la lengua o de la praxis para producir sentido apuntando a la realidad, en este caso se supone que el sentido es producido por la misma organización interna del decir y de la praxis. Se entiende, además, que las relaciones entre elementos son precisamente la infraestructura cultural o ideológica desde la que cada cual, según sea su posición social, percibe e interpreta el mundo. En la perspectiva contextual lo que interesa es la dimensión contextual del componente simbólico. Aquí el sentido se entiende que tiene que ver con el contexto (vivido -caso de las historias de vida- y presente -caso de la observación participante-) que complementa o contradice lo que explícitamente se hace o se dice. Esta parte de la cultura a menudo resulta de muy difícil acceso a quienes trabajan con las técnicas de la perspectiva estructural aunque algo de ella se pueda intuir. Por último, en la perspectiva dialéctica interesa al investigador el componente 
semiótico del lenguaje, lo que hay de fuerza en el habla. En este caso no importa el sentido que pueda proporcionar la lengua sino su capacidad para inscribirse en cursos de acción e incluso para desencadenarlos.

Cuadro 3. Características de las perspectivas distributiva, estructural, contextual y dialéctica.

\begin{tabular}{|c|c|c|c|c|}
\hline & DISTRIBUTIVA & ESTRUCTURAL & CONTEXTUAL & DIALECTICA \\
\hline $\begin{array}{l}\text { DISPOSITIVO } \\
\text { PRODUCTOR } \\
\text { DE INFOR- } \\
\text { MACION }\end{array}$ & $\begin{array}{l}\text { Juego lenguaje } \\
\text { Pregunta/Respuesta } \\
\text { Juego Interacción } \\
\text { Estímulo/Respuesta }\end{array}$ & $\begin{array}{c}\text { Juego lenguaje } \\
\text { Conversación }\end{array}$ & $\frac{\text { uego Interacción }}{\text { Participación }}$ & $\frac{J_{\text {Juego lenguaje }}}{\text { e interacción }}$ \\
\hline $\begin{array}{l}\text { ASPECTO DE } \\
\text { LA INFOR- } \\
\text { MACION OB- } \\
\text { JETO DE } \\
\text { ANALISIS }\end{array}$ & $\begin{array}{l}\text { Dimensión } \\
\text { Referencial } \\
\text { (Denotación) }\end{array}$ & $\begin{array}{l}\text { Componente } \\
\text { estructural de } \\
\text { Dim. Simbólica } \\
\text { (Connotación) }\end{array}$ & $\begin{array}{l}\text { Componente } \\
\text { contextual de } \\
\text { Dim simbólica } \\
\text { (Interpretación) }\end{array}$ & $\begin{array}{l}\text { Dimensión } \\
\text { Pragmática } \\
\text { (Uso) }\end{array}$ \\
\hline $\begin{array}{l}\text { HIPOTESIS } \\
\text { SOBRE LO } \\
\text { SOCIAL }\end{array}$ & Individuos & $\begin{array}{l}\text { Individuos + } \\
\text { Relaciones }\end{array}$ & $\begin{array}{l}\text { Individuos + } \\
\text { Relaciones + } \\
\text { Contexto }\end{array}$ & $\begin{array}{l}\text { Individuos + } \\
\text { Relaciones + } \\
\text { Contexto + } \\
\text { Cambio }\end{array}$ \\
\hline $\begin{array}{l}\text { REFLEXIVID AD } \\
\text { DEL OBJETO }\end{array}$ & Mínima & Media & Media-máx & Máxima \\
\hline $\begin{array}{l}\text { DIRECTIVIDAD } \\
\text { DEL SUJETO }\end{array}$ & Máxima & Media & Mínima-med & Mínima \\
\hline $\begin{array}{l}\text { BASE } \\
\text { METODOLOGICA }\end{array}$ & Matemáticas & $\begin{array}{l}\text { Lingivística } \\
\text { (Semántica) } \\
\text { Psicoanálisis }\end{array}$ & $\begin{array}{l}\text { Lingứstica } \\
\text { (Pragmática) } \\
\text { Antropología }\end{array}$ & $\begin{array}{l}\text { Pedagogía } \\
\text { Psicoanólisis } \\
\text { Cibernética }\end{array}$ \\
\hline $\begin{array}{l}\text { PROPIEDADES } \\
\text { DE LA ACCION } \\
\text { SOCIAL } \\
\text { ANALIZADAS }\end{array}$ & Métricas & Semánticas & Pragmáticas & $\begin{array}{l}\text { Autoorgani- } \\
\text { zadoras }\end{array}$ \\
\hline
\end{tabular}

Una tercera cuestión que conviene tener en cuenta para disitinguir las perspectivas mencionadas es la hipótesis sobre lo social que de un modo espontáneo se activa con cada técnica. No es una formulación teórica explícita sino una especie de "filosofía espontánea" (Althusser, 1985: 76) inscrita en la 
misma técnica y que tiene su origen en las ideologías y teorías que pueblan la sociedad. En cierto modo las técnicas, del mismo modo que sucede con los artefactos que hay en los laboratorios de los científicos duros, no son sino elecciones teóricas e ideológicas reificadas y objetivadas. En el caso de la perspectiva distributiva puesto que con la encuesta tomamos individuos aislados se diría que la hipótesis que se tiene sobre la sociedad es que está formada por una simple colección de individuos con ideas y opiniones propias. En cambio, en la perspectiva estructural, puesto que provocamos que los individuos conversen, como sucede con el grupo de discusión, da la impresión de que la sociedad se supone formada por individuos que se relacionan entre sí, en este caso conversacionalmente. Por su parte, la perspectiva contextual, puesto que presta atención a los sentidos depositados en el contexto y a la interpretación que le dan sus habitantes se diría que la sociedad es algo más compleja pues estará formada por individuos, relaciones y contextos. Finalmente, la perspectiva dialéctica, puesto que engloba técnicas que pretenden intervenir en la realidad social alterándola, parece asumir una visión más compleja que las anteriores pues a los individuos, las relaciones y el contexto habría de sumarse el cambio, más exactamente la variable temporal ${ }^{3}$.

El cuarto asunto al que conviene referirse tiene que ver con la reflexividad reconocida al "objeto" investigado y que guarda una relación inversamente proporcional con la que proyecta el sujeto investigador, por mucho que pretenda borrarse y convertirse en mero algoritmo. En este sentido, se puede observar una gradación desde la perspectiva distributiva a la dialéctica. En la primera la reflexividad del sujeto es máxima y la del objeto mínima pues el primero construye cuestionarios cerrados y al segundo sólo le queda la libertad de elegir una de las respuestas decididas de antemano. En las perspectivas estructural y contextual el investigador inhibe gran parte de su

3 No me refiero al tiempo objetivo sino al vivido y producido por las instituciones o la sociedad. Para el primero hay cada vez más métodos de análisis -técnicas de panel, el análisis de acontecimientos históricos, etc -, en cambio respecto al segundo la ciencia no puede decir mucho pues debe ser experimentado y construido. En esta dirección apuntan las técnicas de la perspectiva dialéctica. 
protagonismo y reconoce gran libertad a los entrevistados e incluso permite la introducción de su contexto en la investigación. Por último, en la perspectiva dialéctica, la reflexividad del investigador se reduce al mínimo y la soberanía del objeto investigado se eleva al máximo.

\subsection{Nivel epistemológico: ¿Para qué?}

Desde un punto de vista epistemológico todas las técnicas de investigación y perspectivas son formalmente idénticas, salvo la dialéctica, pues la investigación social se inscribe en un dispositivo heterónomo de construcción social por el que las élites obtienen información de las bases para pasar a diseñar estrategias de optimización de su poder más efectivas. En cambio, con la perspectiva dialéctica tiene lugar un importante cambio pues se reconoce autonomía cognitiva y práxica al objeto para producir información y decidir actuar a partir de ella. El investigador se convierte prácticamente en un simple testigo que toma nota y tutoriza el proceso de autopoyesis ensayado por su objeto. Es cierto que estas técnicas interventivas están también incluidas, como las otras técnicas de investigación, en dispositivos de dominación pues suelen ser siempre élites las que demandan realizar intervenciones de esta clase. Sin embargo, aunque ése sea el contexto, la investigación ensaya un estilo de acción contrario.

Este último asunto permite dar paso a una cuestión también considerada por lbáñez. Se trata del hecho de que más allá de la investigación, después de la perspectiva dialéctica, hay una situación que de hecho actúa como atractor de la investigación social según pasamos de una perspectiva a otra pero que nada tiene que ver ya con la producción de conocimiento científico. Se trata de la revolución, esa contraimagen de la modernidad que ha estado siempre presente en el proceso de autoinstición de lo social. En efecto, el paso de la premodernidad a la modernidad es el tránsito de un escenario en el que todo está absolutamente determinado de antemano, y resulta por lo tanto conocido (según las necesidades de conocimiento tenidas entonces), a una situación en la que el reconocimiento de ciertas libertades permitirá la aparición de un montante de incertidumbre considerable. Precisamente esa 
incertidumbre es la que ha permitido a la sociedad moderna tornarse tan dinámica y experimentar tan importantes cambios. Sin embargo, el exceso de libertad e incertidumbre debe ser controlado para evitar que el sistema se disipe y desintegre. De modo que la sociedad moderna está instalada en una tensión o contradicción pues requiere de la libertad y de la incertidumbre para incrementar su complejidad pero necesita tenerla controlada. Dicho al modo de Luhmann (1998: 258-259), la sociedad es un sistema en permanente estado de revolución que saca energía para incrementar su complejidad de su estado de desintegración permanente.

Desde este punto de vista se entiende que la función de la investigación social haya sido la de reducir la incertidumbre derivada del incremento de libertad. Sin embargo, esto se ha hecho en etapas. En efecto, la sociedad moderna ha ido incrementando progresivamente su nivel de incertidumbre debido a que cada vez más componentes han sido liberados, lo que ha exigido la intervención de técnicas de investigación y perspectivas no sólo diferentes sino también más potentes. Aunque pueda parecer que la acción de la sociedad de liberar cada vez más partes de lo social y la de la investigación social de reducir la incertidumbre sean independientes, ambas forman parte de un mismo proceso de autoinstitución ensayado desde las élites por el que la sociedad crece y se hace más compleja desintegrándose y reordenándose, liberando componentes y partes luego reanclados y tutelados gracias a los saberes y haceres expertos de científicos y políticos o técnicos (como los de marketing).

La liberación de los individuos producido por el capitalismo de producción y la democracia liberal requerirá de técnicas de investigación centradas en los individuos, como sucede con la Encuesta, que faciliten su control 0 , al menos, el conocimiento de sus opiniones y actos. En segundo lugar, la liberación de las relaciones que tiene lugar con el movimiento de las Relaciones Humanas en el ámbito de la empresa y el capitalismo de consumo o grupalista (después de haberse constatado a nivel clínico -psiquiátrico y psicoanalítico- que el grupo es el lugar donde el sujeto se cura o redime de ciertos problemas derivados de la individualidad) exigirá un conocimiento de ese 
lado informal desatendido hasta entonces, el de las relaciones interindividuales, con las técnicas encuadradas en la perspectiva estructural para tenerlo mejor controlado. En tercer lugar, la progresiva circulación de culturas desancladas de sus contextos de origen así como sus combinaciones y reanclajes en intervalos espaciotemporales distintos ha exigido un control de este nivel contextual de la realidad que han facilitado las investigaciones antropológicas (más que sociológicas, aunque la Escuela de Chicago es una excepción) con técnicas como las historias de vida o la observación participante. Pues bien, hay un último movimiento liberador de carácter sistémico y que está teniendo lugar actualmente. Se trata del interés por controlar las motivaciones, las éticas y la participación en los centros de trabajo. Se trata también de esa responsabilización que se pide a los ciudadanos en la gestión de sus vidas en plena retirada del Estado del Bienestar. Y se trata, por último, de esa democracia participativa que los movimientos sociales piden y practican. Todos estos cambios dan la impresión de formar parte de una liberación de lo social en términos sistémicos. Pues bien, para garantizar el control en este complejo contexto son necesarias las técnicas encuadradas en la perspectiva dialéctica y que cada vez son más utilizadas. La diferencia entre esta última clase de técnicas y las otras es que no están separados los procesos de liberación de partes de lo social y el posterior conocimiento y control proyectados sobre ellas por los científicos y políticos o técnicos. Ambos procesos suceden a la vez. Pero es que, además, con esta clase de técnicas, la distinción jerárquica entre los de arriba, las élites, y los de abajo, la gente, se debilita pues es ésta última la que tiene la mayor parte del protagonismo en la autoorganización. Sin embargo, esta autonomía no es absoluta pues aún las élites tutelarán y conducirán el proceso de autoorganización sistémico ensayado desde abajo. El sociólogo que así actúe realizará una labor muy parecida a la que ensaya el psicoanalista con sus pacientes cuando les deja que recuperen su memoria para sanar el yo. En ambos casos estamos ante una experiencia límite en la que lo instituido se relaja lo máximo que puede para permitir mayor manifestación de lo instituyente. Es un caso extremo en el que lo instituido reconoce implícitamente que se debe a lo instituyente y que no es nada sin su potencia. 
Cuadro 4. Anamnesis y control de sociabilidades que facilitan las perspectivas de la investigación social.

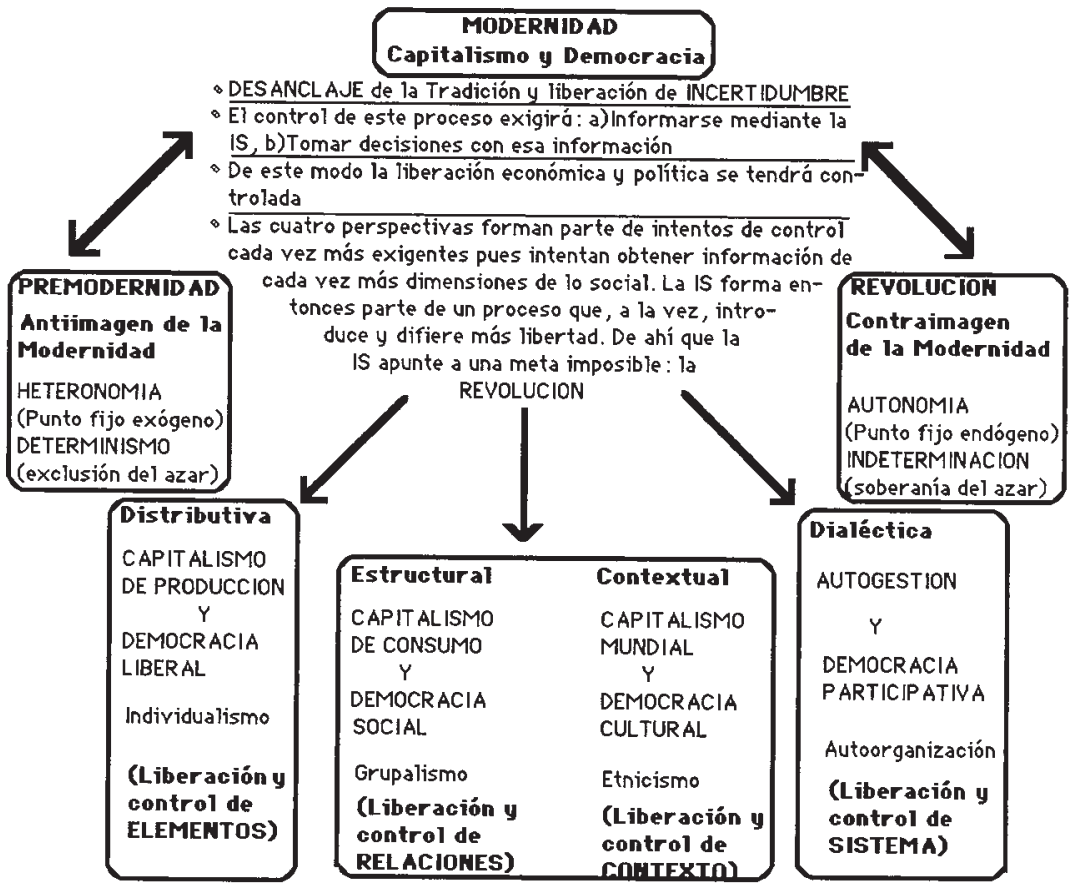

La revolución, ese atractor que inspira la complejización de la investigación social, consistiría en pasar de esa liberación sistémica, pero local y controlada, demandada hoy por las élites y tutorizada por los profesionales de la investigación, a una liberación global en la que no fuera posible el control ni la investigación social. Dicho de otro modo, la revolución consistiría en una autoorganización que sólo puede darse en situaciones altamente metaestables o alejadas del equilibrio. Ahora bien ¿es posible provocar esas situaciones o sólo suceden de un modo espontáneo?. Esta pregunta es importante. Sin embargo, antes de responderla conviene volver al asunto de las anamnesis y reinterpretarlas según lo expuesto a propósito de las técnicas de investigación social. Después estaremos en mejores condiciones para responder a la pregunta. 


\section{Por una Crisología}

La reflexión sobre la sociedad instituida la efectúa la sociología. Entre la política y la sociología se establecen relaciones de mutua complementariedad de las que resultará un fortalecimiento de ese tipo de orden. No obstante, frente a la sociedad instituida hay siempre y en todo lugar un desorden, una heterogeneidad, que es impulsada por la gente. Analizar la realidad social poniendo en un primer plano lo instituyente exige distinguir las situaciones aparentemente estables de las metaestables. En las situaciones aparentemente estables, puesto que la potencia instituyente es capturada y sublimada con éxito por el orden instituido, da la impresión de que la sociedad instituida es lo único existente. Visto desde otro punto de vista, más amable y eufemístico, sucede como si se hubieran alcanzado consensos estables en los que lo instituyente "acepta" ser el contenido de lo instituido. Al margen de cómo sea descrita esta situación lo cierto es que, como la potencia instituyente no aparenta influir gran cosa en el orden instituido, el observador puede describir de un modo creíble y aceptable lo social siendo positivista y no reconociendo más socius que el instituido. Este saber contribuirá a apuntalar teóricamente el orden político. Por su parte, el participante de la vida colectiva resultará alienado, desconocerá el carácter arbitrario de la realidad entre la que se mueve y no tendrá conciencia de que fue creada por él y se sostiene gracias a su aceptación tácita4.

Es obvio que en este escenario no hay lugar para la ciencia crítica. Y es que, del mismo modo que el psicoanalista no puede decir nada del inconsciente si no es a partir de esos fallos en la conciencia que son los los lapsus, síntomas y sueños, tampoco al sociólogo que no sea positivista le resultará accesible la potencia de lo social si no quiebra, aunque sólo sea por un instante, el orden instituido. Sin embargo, las miradas que prestan atención no a las grandes estructuras sino a la

\footnotetext{
4 “El lenguaje de autoridad gobierna siempre con la colaboración de aquellos a quienes se gobierna, es decir, mediante la asistencia de los mecanismos sociales capaces de producir esta complicidad, fundada en el desconocimiento, y que es el origen de toda autoridad" (Bourdieu, 1999: 73)
} 
vida cotidiana pueden tener la oportunidad de comprobar que el orden resulta aceptado porque es interpretado o apropiado de modos muy singulares. Tal enfoque da a entender que el monótono y redundante orden instituido es sólo un velo tras el que se esconden procedimientos, placeres y saberes muy diversos.

Las únicas situaciones en las que la ciencia social puede tomar conciencia clara del espesor de lo social así como de su complejidad son las "crisis" (Morin, 1994: 162-168). Son el segundo modo de relación entre lo instituyente y lo instituido que debe considerarse. Sin embargo, las crisis pueden ser de distintas clases.

En primer lugar, puede suceder que el poder instituido, consciente de los efectos devastadores que puede tener el retorno descontrolado de la potencia instituyente, o simplemente para aliviar tensiones, facilite su "anamnesis local", bien para oxigenar la vida social, como sucede desde tiempo inmemorial con esa anamnesis local tutelada que es la fiesta ${ }^{5}$, o bien para solucionar conflictos, como pasa desde hace menos de medio siglo con el uso de distintas técnicas, el análisis institucional (Lourau, 1988) o la Investigación-Acción-Participativa (Fals Borda, 1993). En tales casos es posible interpretar las anamnesis o como dispositivos más eficaces de control social ejercido por los que mandan o como liberaciones de la potencia instituyente. Las dos observaciones son posibles. Sin embargo, al margen de la valoración que proyecte el observador, no debe dudarse de que es sólo ante estas crisis cuando puede presenciar directamente las complejas relaciones que se establecen entre lo instituido y lo instituyente. Por otro lado, en esas crisis el instrumental teórico y metodológico positivista se

\footnotetext{
${ }^{5}$ No sólo la fiesta, también la comicidad, lo sagrado y otras actividades ex-céntricas son toleradas. Berger (1999: 326), que ha relacionado lo cómico y lo religioso con la locura, dice que ambos fenómenos producen un ex-tasis, un estar fuera de la realidad ordinaria. Y añade: "estos éxtasis son tolerables y, de hecho, útiles, si son transitorios y permanecen cuidadosamente controlados"... "En pequeñas dosis ... estas experiencias vienen a ser como unas vacaciones de la vida. El riesgo está en que alguien pueda decidir tomarse unas vacaciones permanentes... Para mitigar este riesgo se ha confinado tanto a la religión como a lo cómico a lugares y momentos específicos". En un sentido parecido véanse las observaciones de Maffesoli (1993a: 149-185)
} 
devaluará y el observador experimentará una disminución de su saber proporcional tanto al vacío de sociedad instituida generado como al montante de alteridad instituyente asomada. En tales casos es necesario cambiar de estilo de reflexión y proponer un "no-saber" o un "quasi-saber". . Este saber que no se sabe (o que sabe menos) es un pensamiento reflexivo, de segundo orden, pues deja de prestar atención al objeto y permite que entre en escena el proceso de observación mismo.

En segundo lugar, es posible que la anamnesis local se produzca también de un modo no tutelado o dirigido sino espontáneo debido a que la potencia instuyente no se reconoce en las desgastadas o excesivamente opresivas estructuras instituidas e irrumpe en la superficie dispuesta a autoorganizarse. Es lo que ha ocurrido a partir de algunas fiestas, espectáculos deportivos y conflictos políticos. Pueden tener lugar también con ocasión de las intervenciones socioanalíticas, caso de Mayo del 68, si es cierto, como asegura Ibáñez (1994: 85), que este estallido tuvo su origen en un socioanális tutelado por René Lourau, que interpretó el deseo de ocupar el Rectorado de la Universidad de Nanterre en términos de acting out. Pero sucede también con las delincuencias, las locuras y otras conductas calificadas como anómicas. El problema es que estas emergencias se manifiestan como rechazos o réplicas patológicas frente a la opresión de lo instituido, no como afirmación autónoma de otro modo de ser, de pensar y de hacer.

Ante la emergencia local de éstas u otras alteridades instituyentes que reaccionan contra lo instituido, la sociedad no se resignará. En unos casos utilizará profesionales o instituciones especializados en la vigilancia y reconducción de tal o cual clase de sociabilidades. En otros casos, si falla la estrategia

\footnotetext{
6 También sería necesario activar estrategias distintas a las políticas. Lee y Brown (1998: 219-248) las denominan "fractales": "son menos que una estrategia pero más que nada". El problema de la sociología es que se ha implicado tanto en la construcción de lo instituido que se ha sentido en la necesidad de tener que hablar de y por todo el mundo. Pues bien, en las situaciones de crisis puede tomarse conciencia de que tal modo de actuar debe ser sustituido por otro más débil, más cercano al no hacer, pues sólo así puede tomarse nota de la alteridad emergente y respetar su singularidad. Dicho de otro modo, debe bloquearse lo más posible la voluntad de traducirlo todo. En un sentido parecido véanse las observaciones de Maffesoli (1993a: 149-185)
} 
anterior, directamente encerrará a los sujetos. Y siempre teniendo a la sociología y otras ciencias sociales como instrumento de apoyo teórico que facilite la comprensión y predicción de lo anómalo.

El problema de las anamnesis locales, tuteladas-provocadas o espontáneas, es que si las alteridades socialitarias no son capaces de autoorganizarse afirmando su propia producción de sentido y lo toman prestado de la sociedad o permiten que ésta se los otorgue puedan caer en situaciones de doble vínculo ${ }^{7}$, Los autores de Palo Alto (Watzlawick, Beaven y J ackson, 1985: 196 y ss.) han observado que en una situación familiar, dadas unas relaciones jerárquicamente complementarias con gran valor de supervivencia física y/o psicológica para uno de sus miembros, la exposición a un mensaje en el que el enunciado o texto y la enunciación o contexto se contradicen impide una respuesta coherente. Si el destinatario intenta desbordar ese marco de interacción para reconciliarse con el sentido pero no es capaz de producir uno realmente nuevo la familia convertirá esos ensayos liberadores en patologías paranoicas, esquizofrénicas, catatónicas o hebefrénicas.

Pues bien, del mismo modo, si las alteridades socialitarias asomadas en las anamnesis no son capaces de afirmarse autónomamente y se orientan según los sentidos aún disponibles en la sociedad que les circunda podrán padecer la transformación de su esfuerzo de liberación en diversos pathos anómicos. Es, por ejemplo, lo que sucede con los jóvenes, protagonistas de múltiples ensayos de autoorganización en los que tienden a afirmarse sentidos existenciales distintos a los instituidos. Avello Flórez y Muñoz Carrión (1989) han observado que tales impulsos, si no rompen sus cadenas con la sociedad, pueden acabar dando lugar a conductas anómicas, como el consumo compulsivo de drogas, el vandalismo, etc. Sin embargo, para el observador atento tales manifestaciones anómicas son índices de alteridades que, aunque han fallado en su autoorganización, han logrado hacerse notar reactivamente. Sobre ese no ser,

\footnotetext{
${ }^{7}$ Acerca de las diferentes interpretaciones que se ofrecen del concepto véase Bateson (1991: 236-241),Wilden (1979: 121-22, 127 y 222-23), Anzieu (1986: 166-67), Ibáñez (1985b: 54-55) y Deleuze y Guattari (1985: 85-86)185)
} 
que no se limita a no ser sino que quiere ser, debe centrar su saber que no sabe el observador.

Otro ejemplo. Wieviorka (1992: 254) ha observado que en un contexto de desestructuración del vínculo asociativo, como es el caso en la actual crisis de la modernidad (y de sus movimientos sociales clásicos -el obrero-, su Política, el EstadoNación, etc.), tienden a emerger vínculos comunitarios. Pues bien, si para los mismos se proponen representaciones que, aun producidas desde la experiencia comunitaria, intentan emular a las desaparecidas de la sociedad y dar lugar a una nueva unidad ideal, es probable que emerja el racismo. Conviene subrayar que el racismo no deriva entonces del vínculo comunitario sino más exactamente del deseo de recomponer cierta unidad reparando la tutela de una sociedad en crisis, que todavía no ha llegado o que ya ha desaparecido. Es precisamente ese deseo alienado el que está en la base del racismo.

Un último ejemplo lo proporciona la contemporánea proliferación de sectas (Delgado, 1999: 131 y ss.). Aparecen en un contexto de déficit, descomposición o falta de realidad institui$\mathrm{da}$, de sociedad, ante el que emerge y se libera un deseo de organicidad, de comunidad. La falta de sociedad tiene que ver con la pérdida de vínculos identitarios, desarraigo social, pérdida de objetivos existenciales, etc. Sin embargo, las respuestas, sentidos y soluciones que las sectas proporcionen a esa falta crearán "sociedades intersticiales". Es decir, sustitutos de una sociedad que ha fallado (como sucede actualmente) o que todavía no existe (es el caso del pentecostalismo entre los colonos norteamericanos). De modo que las sectas, esos simulacros de sociedad, "aparecen en las grietas, en las brechas del sistema, pero no para ensancharlas ... si no para soldarlas, para taponarlas" (p. 137). No son pues una amenaza al orden instituido sino su réplica sustitutiva.

La última de las tres situaciones mencionadas más arriba que queda por citar es la anamnesis global espontánea con la que se entra en una situación de pánico que abolirá el orden instituido y facilitará la autoorganización al nivel de las sociabilidades primarias. Esta clase de anamnesis tiene lugar en las revoluciones y será permanentemente recordada por las socie- 
dades que sobre las socialidades liberadas se construyan. A diferencia de lo que sucede con las distintas clases de anamnesis local o crisis vistas antes, aquí el observador no podrá comprender nada pues los puntos fijos exógenos a partir de los cuáles podía observar y evaluar habrán sido absolutamente eliminados. El no ser en el objeto y el no saber en el observador habrán sustituido cualquier rastro de ser y de saber.

De esto se deduce el trágico y paradójico papel que deberá saber aceptar el científico social comprometido con la liberación de las alteridades reprimidas. No podrá, a la vez, conocer y liberar las alteridades pues si las conoce es que están aún reprimidas, aunque sea parcialmente, y si se liberan del todo ya no podrá conocerlas pues la misma atalaya societaria desde la que se identificó con lo que no cabía en el orden instituido habrá desaparecido. En tales revoluciones el observador se verá obligado a transformarse en participante interno $\mathrm{y}$, en tanto que tal, deberá desenvolverse utilizando su intuición y saber práctico. La sociología se habrá desvanecido.

En la actualidad, con la crisis de los metarrelatos de legitimación ideológicos y científicos producidos en la modernidad se están dando múltiples anamnesis locales espontáneas que los poderes instituidos intentan reciclar a marchas forzadas, lo que no siempre logran, para permitir la transformación ordenada de la sociedad. Por eso dos de las principales tareas que deben afrontar las investigaciones sobre lo social en su actual momento de crisis son: observar la liberación de potencia instituyente que contemporáneamente se produce y comprobar cómo problematizan en cada caso los antiguos metalenguajes de la sociedad esas desterritorializaciones produciendo, si se dan las condiciones, situaciones de doble vínculo.

Para el científico social estas crisis que padecemos en el ocaso de la modernidad son magníficos puestos de observación para darse cuenta de la complejidad de lo social. Permiten también percibir de un modo privilegiado la importancia de las sociabilidades primarias, esa auténtica infraestructura de lo social. Y dan, por último, la ocasión de reconocer con honestidad que lo mucho que no se sabe es una medida de la vitalidad de lo instituyente y, con él, de lo social en su conjunto. 


\section{Exoducción}

Volvamos a la pregunta planteada más arriba según lo sugiere lo acabado de exponer acerca de las anamnesis. Ahora quedaría reformulada del siguiente modo: ¿cómo hacer para provocar anamnesis globales?. Quizás lo que haga falta sea un "hacer" que no haga del modo clásico o convencional, como sucede con las intervenciones de las Administraciones, pues así, aunque se confíe en dar algo de cabida a lo instituyente, sólo se hace que apuntalar lo instituido. Si el "hacer" ha estado siempre al servicio de lo instituido, para permitir la anamnesis y posterior autoorganización de lo instituyente es pues necesario "no hacer". En esa dirección apunta el wu wei taoísta. Se ha solido traducir este término por "no hacer". Sin embargo, la traducción correcta bien podría ser esta otra: "no hacer nada y que nada quede sin hacer" (J ullien, 1999: 139). No estamos ante un mero juego de palabras sino ante una concepción del "hacer" distinta a la que ha sido habitual en la interventiva mentalidad occidental. Este otro modo de hacer quizá haya sido mejor formulado por el hinduismo. En el Canto II del Bahagavad Gita, uno de los textos fundacionales del hiduísmo, se dice: "Tú debes perseguir la acción, pero jamás a sus frutos; que éstos no sean tu acicate" (V. 47). Actuar por actuar, sin ligarse a lo instituido, confiando en la capacidad de hacer acontecer que trae consigo lo instituyente, tal parece ser la sugerencia de este singular modo de actuar.

El modo de actuar occidental es bien distinto: "erigimos una forma ideal, la establecemos como objetivo y con los ojos puestos en el modelo propuesto decidimos intervenir en el mundo y dar forma a la realidad (J ullien, 1999: 19). El problema es que el mundo no es del todo receptivo a este modo de hacer. Por eso la práctica acabará traicionando, aunque sea mínimamente, la teoría. Además, este hacer siempre deja de lado lo no hecho, para siempre irrecuperable, que puede retornar deshaciendo lo que habíamos hecho (p. 141). Por el contrario, el sabio chino, "antes de erigir un modelo que sirva de norma para su acción, concentra su atención en el curso de las cosas para descubrir su coherencia y aprovechar su evolución" (p. 40). En lugar de imponer un plan al mundo se basa en el 
potencial de la situación. Y es que la tradición china siempre fue escéptica respecto a la eficacia atribuida a la acción según modelos pues pensó que no es necesario actuar de ese modo para hacer acontecer (p. 97). A diferencia también de la mentalidad occidental si el "hacer" se refiere al "ser" el "no hacer" tiene principalmente en cuenta el "no ser". Ese "no ser" es el fondo indiferenciado de las cosas. Por eso es inagotable: "dado que el vacío no se enfrenta con nada, no puede suscitar resistencia y, por ende, no se gasta" (p. 175)

En Grecia, antes de aparecer el logos, hubo personajes que se encargaban de provocar anamnesis catárticas practicando un hacer que encaja bastante en el que nos sugiere la tradición china. Uno de ellos es Epiménides (Vernant, 1992: 8889; García Cual, 1989: 159-181). El mérito de este sabio consiste en descubrir las faltas antiguas que engendran estados de perturbación y repararlos mediante ritos expiatorios, purificaciones y fundaciones. Según Aristóteles lo que Epiménides hace es permitir que se reencuentren lo jurídico, lo religioso y lo social. Es decir, reconcilia lo instituido y lo instituyente de un modo parecido a como operan las técnicas dialécticas. Sin embargo, no actúa a nivel local sino global pues afecta a toda la comunidad. Por otro lado, este modo de provocar anamnesis tiene poco de científico pues se inspira en prácticas chamánicas emparentadas con la magia.

En la Grecia inmediatamente anterior a la que vio nacer el logos los siete sabios habían heredado el antiguo y semiolvidado saber chamánico para ponerlo al servicio de la comunidad (García Cual, 1989: 13 y ss). Después de ellos aparecerá el logos y, con él, un nuevo modo de hacer basado en modelos. En cambio, en China, la sabiduría no desapareció, siguió cultivándose. Y con ella el mundo siguió percibiéndose en términos de totalidad no divisible. J usto lo contrario de lo que perciben las técnicas que nos hemos otorgado en la Modernidad, incluidas las de investigación social. Sólo el Análisis Institucional y la Investigación-Acción-Participativa parecen querer escapar de esa tendencia. Sin embargo, actúan en un nivel local y, aunque con matices, todavía forman parte de un modo heterónomo o voluntarista de autoinstitución de lo social. Y lo instituyente no quiere exactamente eso. 


\section{Referencia bibliográfica}

ALTHUSSER, L. (1985): Curso de filosofía para científicos. Barcelona: Planeta-Agostini.

ANZIEU, D. (1986): El grupo y lo inconsciente. El imaginario grupal. Madrid: Biblioteca nueva.

AVELLO FLÓREZ, J. Y MUÑOZ CARRIÓN A. (1989). "Cultura juvenil: la comunicación desamparada", en Rodríguez González, Félix, Comunicación y lenguaje juvenil. Madrid:. Fundamentos

Madrid: CIS.

BERGER, P. (1999): Risa redentora. Barcelona: Kairós

BOURDIEU, P. (1999): ¿Qué significa hablar? Madrid: Akal

DE CERTEAU, M. (1990): L'invention du quotidien, 1. Arts de faire. Paris: Gallimard.

DELEUZE, G. Y GUATTARI, F. (1985): El Antiedipo. Esquizofrenia y capitalismo. Barcelona: Paidós.

DELGADO, M. (1999): El animal público. Barcelona: Anagrama.

DUVIGNAUD, J. (1990): La solidaridad, México: Fondo de Cultura Económica.

FALS BORDA, O. (1993): "La investigación acción participativa y la intervención social", en Documentación social, № 92. Madrid: Cáritas.

FREUD, S. (1982): El malestar en la cultura. Madrid: Alianza.

GARCÍA CUAL, C. (1989): Los siete sabios (y tres más). Madrid: Alianza

GUATTARI, F. (1990): Las tres ecologías. Valencia: Pre-textos. IBÁÑEZ, J . (1985a): Más allá de la sociología. El grupo de discuisión. Técnica y crítica. Madrid: Siglo XXI

(1985b): Del algoritmo al sujeto. Perspectivas de la investigación social. Madrid: Siglo XXI. 
(1994): Por una sociología de la vida cotidiana. Madrid: Siglo XXI.

J ULLIEN, F. (1999): Tratado de la eficacia. Madrid: siruela

LAPASSADE, G. (1996): La bio-energía. Ensayo sobre la obra de W. Reich. Barcelona: Gedisa.

LIPOVETSKY, G. (1988): El imperio de lo efímero. Barcelona: Anagrama

LOURAU, R. (1988): El estado y el inconsciente. Barcelona: Kairós.

LUHMANN, N. (1998): Sistemas Sociales. Barcelona: Anthropos.

LEE, N. Y BROWN, S. (1998): "La alteridad y el actor-red. El continente no descubierto". Domènech, M. y Tirado, F. J . (comps.), Sociología simétrica, Barcelona, Gedisa, pp. 219-248 MAFFESOLI, M (1982): La violencia totalitaria. Barcelona: Herder.

(1992): La trasfiguration du politique. Paris: Grasset.

(1993a): El conocimiento ordinario. México: F. C. E.

(1993b): La contemplation du monde. Paris: Grasset

MARTín SANTOS, L. (1988): Diez lecciones de sociología. Madrid: Fondo de Cultura Económica.

MATURANA, H. Y VARELA, F. (1990): El árbol del conocimiento. Las bases biológicas del conocimiento humano. Madrid: Debate.

MORIN, E. (1994): Sociología. Madrid: Tecnos

PRIGOGINE, I. Y STENGERS, I. (1990). La nueva alianza. La metamorfosis de la nueva ciencia. Madrid: Alianza.

SIMONDON, G. (1989): L'individuation psychique et collective. Paris: Aubier. 
VARELA, J . Y ALVAREZ URÍA, F. (1986): Las redes de la psicología. Madrid:Ediciones Libertarias.

VERNANT, J . P. (1982): Los orígenes del pensamiento griego. Barcelona: Piados.

WATZLAWICK, P. BEAVEN, H. Y J ACKSON, D. (1985): Teoría de la comunicación humana. Barcelona: Herder

WIEWIORKA, P. (1992): El espacio del racismo, Barcelona: Paidós.

WILDEN, A. (1979): Sistema y estructura. Madrid: Alianza. 